Geopolítica(s) Revista de estudios sobre espacio y poder ISSN: 2172-3958

\title{
Un impulso para la Geografía Electoral: el uso de tecnologías geoespaciales para el análisis del voto de las comunidades hispanas en Estados Unidos ${ }^{1}$
}

\author{
Ryan Weichelt ${ }^{2}$
}

Recibido: 6 de julio de 2017 / Aceptado: 1 de septiembre de 2017

Resumen. Las primeras investigaciones electorales analizaban las elecciones considerando unidades de área ecológica compactas, tales como los estados, para examinar cómo se votaba. Sin embargo, en la década de 1920, la ciencia política comenzó a centrarse en el comportamiento del votante individual, volviéndose cada vez más dependiente de los datos de la encuesta. La geografía electoral que también recurría a encuestas encontraba problemática esta aproximación metodológica debido a la dificultad de conectar patrones de votación geográfica con las encuestas individuales. En la década de 1960, el surgimiento del positivismo recondujo a los geógrafos/as electorales hacia el estudio del comportamiento electoral de grupos grandes sobre datos agregados, no individuales. Si bien los métodos cualitativos aún tienen un papel importante en la investigación electoral, el crecimiento de las tecnologías geoespaciales y el aumento de los intereses en la cartografía electoral podrían proporcionar hallazgos importantes y deberían utilizarse más en el estudio de las elecciones. Este artículo señalará una variedad de técnicas de análisis espacial (es decir, métodos cartográficos, estadísticas espaciales y autocorrelación espacial) aplicadas al análisis de los patrones electorales más recientes del voto de las comunidades hispanas en Estados Unidos. Al proporcionar una discusión sólida de los métodos de análisis geoespacial, nuestro objetivo es proporcionar nuevas líneas de debate sobre el papel de la geografía en las elecciones de estudio.

Palabras clave: geografía electoral; voto hispano; Estados Unidos; análisis espacial; tecnologías geoespaciales.

\section{[en] Enhancing Electoral Geography: Utilizing Geospatial Technologies to} Analyze Recent Hispanic Voting Patterns in the United States

\begin{abstract}
Early electoral research analyzed elections as whole areal ecological units such as individual states to examine how people voted. However, in the 1920s, political scientists began to place a strong emphasis on individual voter behavior, becoming increasingly reliant on survey data. Electoral geographers who utilized surveys were always troubled with this method due to the difficultly of connecting geographic voting patterns to individual respondents. The rise of positivism in the 1960s, inspired electoral geographers to re-center their focus on the voting behavior of large groups in the aggregate, not the individual. While qualitative methods still have an important role to play in electoral inquiry, the growth of geospatial technologies and increased interests in electoral cartography can yield important
\end{abstract}

\footnotetext{
1 Traducido del original en inglés por María Lois.

2 Department of Geography and Anthropology, University of Wisconsin-Eau Claire (Estados Unidos)

E-mail: weicherd@uwec.edu
} 
insights and should be utilized more in the study of elections. This paper will highlight a variety of spatial analysis techniques (i.e. cartographic methods, spatial statistics, and spatial autocorrelation) focusing on the recent electoral patterns of Hispanic voters in the United States. By providing a robust discussion of geospatial analysis methods, this paper can provide new avenues of discussion regarding geography's role in the study elections.

Keywords: electoral geography; Hispanic voting; USA; spatial analysis; geospatial technologies.

\section{[pt] Um impulso para a Geografia Eleitoral: o uso de tecnologias geo- espaciais para a análise do voto das comunidades hispanas em Estados Unidos}

Resumo. As primeiras investigações eleitorais analisavam as eleições considerando unidades de área ecológica compactas, tais como os estados, para examinar como se votava. No entanto, na década de 1920, a ciência política começou a centrar no comportamento do votante individual, voltando-se a cada vez mais dependente dos dados da pesquisa de opinião. A geografia eleitoral que também recorria a pesquisas de opinião encontrava problemática esta aproximação metodológica devido à dificuldade de ligar padrões de votação geográfica com as pesquisas de opinião individuais. Na década de 1960, o surgimento do positivismo devolveu aos geógrafos/as eleitorais para o estudo do comportamento eleitoral de grupos grandes sobre dados agregados, não individuais.. Conquanto os métodos qualitativos ainda têm um papel importante na investigação eleitoral, o crescimento das tecnologias geo-espaciais e o aumento dos interesses na cartografia eleitoral poderiam proporcionar achados importantes e deveriam se utilizar mais no estudo das eleições. Este artigo assinalará uma variedade de técnicas de análise espacial (isto é, métodos cartográficos, estatísticas espaciais e autocorrelação espacial) aplicadas à análise dos padrões eleitorais mais recentes do voto das comunidades hispanas em Estados Unidos. Ao proporcionar uma discussão sólida dos métodos de análises geo-espacial, nosso objectivo é proporcionar novas linhas de debate sobre o papel da geografia nas eleições de estudo.

Palavras-chave: geografia eleitoral; voto hispano; Estados Unidos; análise espacial; tecnologias geoespaciais.

Sumario. Introducción. 1. La Geografía Electoral moderna. 2. Estadísticas espaciales, población hispana y elecciones presidenciales de 2016. 3. Análisis factorial modo T (T-mode) y modo S (S-mode). 4. Regresión espacial. Conclusiones. Bibliografía.

Cómo citar: Weichelt, Ryan (2018) “Un impulso para la Geografía Electoral: el uso de tecnologías geoespaciales para el análisis del voto de las comunidades hispanas en Estados Unidos”. Geopolítica(s). Revista de estudios sobre espacio y poder, vol. 9, núm. 1, 11-34.

\section{Introducción}

La geografía electoral ha sido tradicionalmente considerada como una subdiciplina de la geografía política, que podríamos definir de forma sencilla como la investigación política con perspectiva espacial (Archer \& Shelley, 1986: 11). J. K. Wright escribía que "la geografía política es quizás la dimensión más «humana» de la geografía, ya que trata básicamente con las fortalezas, debilidades y ambiciones de los individuos" (1944: 190).

La geografía electoral es, básicamente, el análisis sistemático y espacial de las elecciones (Shelley et al., 1990) y tiene una larga historia intelectual, que data de principios del siglo XX. Los cambios tecnológicos y la revolución estadística de los años 1950 contribuyeron a su fortalecimiento, pero al mismo tiempo que surgían las 
críticas sobre el lugar que ocupaba la geografía electoral en la geografía política. Shelley et al. planteaban que "la geografía electoral ha sido víctima de un [...] empiricismo rampante [...] Muchos trabajos de geografía electoral son meras descripciones de las tendencias espaciales del voto en una elección en particular, con poca o ninguna preocupación por cuestiones más amplias. De esta manera, la teoría social en la que se apoya este análisis sostiene un modelo de sociedad status quo" (1990: $1)$.

A causa de esta centralidad de lo empírico, desde 1990 a 2010,

[la geografía electoral] ha caído en la senescencia. Mientras en la geografía humana la creciente preocupación por cuestiones conceptuales se resolvía con un acercamiento a diversas formas de teoría social y economía política, la obsesión de los geógrafos electorales con los datos y las técnicas que reflejaban o bien un impenitente positivismo o una visión ingenua, así como su meditado abandono tanto de cuestiones teóricas como de contexto social, dejó a la subdisciplina incapacitada para contribuir sustancialmente a los debates conceptuales contemporáneos (Warf \& Leib, 2011: 3).

Ahora bien, los mismos autores que cuestionaban el valor de las contribuciones de la geografía electoral también planteaban que los avances tecnológicos y la cooperación fuera de la disciplina, fundamentalmente con la ciencia política, renovarían la atención por la geografía electoral en la academia y en el público en general.

Mientras la academia se preocupaba con el intento fallido de los geógrafos electorales de conectar teoría social y análisis empíricos, comenzaba a crecer el interés público en los datos electorales. Un ejemplo concreto sería el popular blog estadounidense de Nate Silver, blog fivethirtyeight.com, donde, usando datos y estadísticas, se interpretan y predicen resultados electorales. Aunque los métodos de Silver ya eran más o menos utilizados por muchos geógrafos electorales en el pasado, ha sido capaz de dar información sobre elecciones, estadísticas, demografía y tecnología al público en general de manera atractiva. De manera similar, la estrategia de campaña del presidente Obama en 2008 llamó la atención por su apoyo en datos espaciales y demográficos a la hora de identificar a los votantes clave de áreas geográficas concretas, en lugares como el condado de Cuyahoga en Ohio (Cleveland) o en el condado de Orange en Florida (Orlando). Esta estrategia de datos intensiva permitió que durante la campaña se concentrasen recursos valiosos en áreas geográficas específicas para conseguir votantes. Con este nuevo estilo de campaña y el creciente interés general en la geografía de las elecciones, los geógrafos electorales se encuentran en una posición privilegiada. Más que ser despreciada como la herramienta arcaica de una geografía política vanguardizada, la familiaridad del geógrafo/a electoral con las tecnologías geoespaciales puede ayudar a disminuir la distancia entre positivismo y teoría social, al tiempo que fortalece el conocimiento espacial del público sobre procesos electorales.

Aunque este artículo no argumenta que las tecnologías geoespaciales sean la salvación de la geografía electoral como disciplina, su objetivo es señalar algunos avances en tecnologías geoespaciales que puedan ser tanto de uso común como un elemento para conectar entre disciplinas o perspectivas teóricas. El texto comenzará exponiendo una evolución concisa de la geografía electoral contemporánea, seguido 
de dos ejemplos específicos sobre cómo las tecnologías geoespaciales pueden ser usadas para desarrollar explicaciones más contextuales en el estudio de las elecciones. Aunque las referencias se concentrarán en los resultados electorales recientes en los Estados Unidos, las técnicas pueden aplicarse en cualquier otro contexto donde haya datos espaciales disponibles.

\section{La Geografía Electoral moderna}

En los años 1950 y 1960, antes de los trabajos de Keys, la geografía electoral estaba sin teoría y sin rumbo. En los años 1940, la geografía política se ocupaba básicamente de estudiar las fronteras internacionales, los límites y las áreas nucleares (Archer \& Shelley, 1986). En torno a 1950, Richard Hartshorne introducía su "perspectiva funcional" en la geografía política, proponiendo que esta debía identificar la raison d'etre del Estado, "básicamente la idea que hace distintiva en un Estado particular en contraste con otros estados" (Hartshorne, 1950: 112). El subsecuente trabajo de Prescott en 1959 intentaba aterrizar la geografía electoral en la "perspectiva funcionalista", argumentando que para que una elección fuese de interés para un geógrafo político funcionalista, esta debía estar relacionada con la raison d'etre de ese Estado (Prescott, 1959: 304; Archer \& Shelley, 1986: 26). Lo que se derivaría de esta aproximación es que una elección sólo es importante si cuestiona la validez del Estado.

Prescott reconoce esta cuestión manifestando que "es normalmente complicado determinar la raison d'etre de los estados largamente establecidos, donde las cuestiones electorales son normalmente complejas y variadas" (1959: 300). Si esta perspectiva se aplicase al estudio de los Estados Unidos, la única elección de importancia habría sido la de ratificación de la Constitución en 1787-1788 (Archer \& Shelley, 1986).

Las dificultades presentadas por la perspectiva funcionalista desaparecieron en los años 1960s y dieron paso a un nuevo pensamiento en geografía electoral. John Agnew divide la geografía electoral reciente en cuatro periodos, desde 1965 hasta la actualidad, que denomina período de modernización-nacionalización; de bienestar demográfico (demographic welfare); el periodo del desarrollo desigual y el microsociológico (Agnew, 1990). Durante el periodo de modernización-nacionalización, que abarcaría de 1965 a 1972, la mayoría de las perspectivas teóricas se basaban en el trabajo de Kevin Cox (1969) "La decisión de voto en un contexto espacial", sobre el que se afirmaba:

[E]ste texto resumía los hallazgos de la tradición de los encuestadores sociales (social surveyor) para una audiencia geográfica y ayudaba a iniciar la investigación sobre los efectos electorales de la difusión espacial de información políticamente relevante a escala micro-espacial[...]los patrones geográficos establecidos para las identificaciones partidistas, basadas en la socialización política, la clase, el status, el carácter étnico etc. Tendían a dominar la configuración de "superficies de respuesta electorales" (Archer \& Shelley, 1986: 27).

Dicho de manera simple, Cox puso "énfasis en los «efectos de vecindario» (los efectos de la distancia en los flujos de información) y las «partisan cues» 
(información en clave partidista) para explicar el comportamiento electoral" (Agnew, 1990: 16). En el contexto estadounidense, Cox argumenta que la homogeneización espacial del voto y la cultura tendrían lugar a través de la integración económica y la conexión de las personas a la información creando una nacionalización del comportamiento electoral (Agnew, 1990). Con el tiempo, la homogeneización espacial de estos efectos reduciría las variaciones regionales del voto, haciéndolas menos significativas.

El siguiente periodo en el desarrollo de la geografía electoral moderna sería el periodo denominado del Bienestar demográfico. La principal premisa de este periodo se basaba en la vinculación entre problemas sociales y distribución y acceso a bienes y servicios públicos: la distribución desigual de estos bienes entre esos grupos definiría su implicación en procesos políticos. Cox (1973) analizaba estas cuestiones en la escala urbana, mientras Brunn (1974) y Johnston (1979) lo hacían en el contexto estatal (Agnew, 1990).

El tercer momento, el periodo del desarrollo desigual, fue señalado en el análisis de las elecciones presidenciales estadounidenses desde 1820 a 1980 realizado por Archer \& Taylor en 1981. Este estudio se apoyaba en el concepto de secciones de Fredrick Jackson Turner, que definían una relación espacial entre un centro y una periferia del poder Democrático y Republicano. Estas diferencias en poder político entre Republicanos y Demócratas se atribuían al desarrollo económico y las tendencias migratorias. Con el desarrollo de las regiones y la integración en los sistemas económicos estatales y mundiales, los conflictos políticos se darían entre regiones respecto al control del gobierno federal (Watrel, 2001). La investigación de Archer \& Taylor mostraba como los patrones seccionales del voto eran evidentes en los Estados Unidos y que estos patrones cambiaban con el tiempo con los cambios en las ideologías de los partidos políticos. Johnston (1977) proponía un análisis similar para los partidos Conservador y Laborista en el caso de Gran Bretaña (Agnew, 1990). Esta perspectiva ha despertado y despierta gran interés en la geografía electoral (Taylor \& Johnston, 1979; Archer \& Shelley, 1986; Trubowitz, 1998; Heppen, 2003; Archer \& Taylor, 1981; Elazar, 1984).

Finalmente, la perspectiva microsociológica habría comenzado en 1979 y continuaría hasta hoy. Esta perspectiva enfatiza el "lugar" como esencial para entender el comportamiento político de cualquier área. Usando una metodología de análisis contextual, la premisa de esta perspectiva es que cada lugar tiene una historia singular y tradiciones locales que subyace al comportamiento político. Mercer \& Agnew (1988) argumentan que "la población vota de diferentes maneras por su «socialización activa» en las diversas orientaciones políticas, que dependerían de la estructura social y de los antagonismos históricos en los diferentes lugares" (Mercer \& Agnew, 1988: 138). La investigación de Agnew (1985) sobre el Scottish National Party (SNP) es un excelente ejemplo del uso de métodos contextuales para entender el comportamiento político (Agnew, 1990). Mientras algunos estudios subsiguientes han utilizado esta perspectiva (Agnew, 1985; Agnew, 1987; Agnew, 1996; Mercer \& Agnew, 1988), la falta de datos empíricos adecuados habría limitado su desarrollo.

Como complemento a estas perspectivas, el objetivo de este artículo es construir un contexto desde el que fortalecer la geografía electoral con herramientas como el análisis de Big Data ayudado por metodologías y tecnologías geoespaciales. Un objetivo secundario sería suministrar a los outsiders de la geografía electoral una mejor comprensión de esta disciplina, frecuentemente ignorada, con la esperanza de que 
haya una mayor cooperación entre todos aquellos que realizan estudios electorales. Para estos propósitos, recurriremos a ejemplos específicos que relacionaremos con resultados electorales recientes en contexto estadounidense contemporáneo, a partir de un acercamiento al voto de las comunidades hispanas.

\section{Estadísticas espaciales, población hispana y elecciones presidenciales de 2016}

Baybeck \& McClurg afirmaban que la "geografia tiene un papel esencial en alguna de las explicaciones del comportamiento político" (2005: 492). De forma más específica, Johnston et al. sugieren que "a causa de la importancia del contexto local tanto en la socialización de votantes como en las actividades de movilización desarrolladas por los partidos políticos [...] donde se vive puede ser un importante factor de predicción del sentido del voto" (2007: 640). Aunque el nivel del análisis geográfico varíe desde el condado y los distritos congresuales en los Estados Unidos a los distritos parlamentarios en Gran Bretaña, sin embargo, todos los estudios indican que existen patrones geográficos sustancialmente diferentes en diferentes escalas, particularmente entre votantes con orígenes diversos en términos culturales, raciales y/o socioeconómicos (Johnston, 1974; Archer \& Taylor, 1981; Shelley \& Archer, 1984; Pattie \& Johnston, 1990; Jones et al., 1992; Agnew, 1996; Tunstall et al., 1997; Pattie \& Johnston, 2000; Ward, 2002; Heppen, 2003; Johnston et al., 2007). La base de la idea del "contexto local" aparece en los primeros trabajos de Kevin Cox, como en el ya mencionado "La decisión de voto en un contexto espacial" (1969), donde acuñaba el término "efecto vecindario". El vecindario, argumenta, es esencial en el comportamiento electoral porque es el cauce para las interacciones sociales donde las personas debaten diversos temas políticos (Taylor \& Johnston, 1979). Johnston sugiere que, ya que la mayoría de las personas trabajan cerca de sus casas e interactúan con vecinos teniendo características socioeconómicas similares, los mapas de resultados electorales deberían ilustrar las diferencias de voto entre grupos (1974: 418).

A partir de las teorías de Cox sobre el vecindario, la geografía expandió su escala de investigación más allá de los impactos del contacto individual, hacia otras influencias, gestándose lo que John Agnew denominó "análisis contextual". Agnew sugiere que la información es la "discriminación/canalización jerárquica de estímulos a través de las escalas geográficas..." e influye en el comportamiento político (1996: 132). La información es transmitida de las unidades domésticas a los vecindarios, las ciudades, los distritos electorales, las regiones y los países, en numerosas escalas, donde cada una diezma la información de diferentes maneras, pero todas ellas con influencia en el comportamiento electoral (Johnston et al., 2007). Los residentes de todas estas escalas podrían desarrollar una identidad común que los predispondría a votar de ciertas formas (Jones et al., 1992: 347). La agregación temporal en los distritos electorales o niveles equivalentes se complica por los frecuentes cambios en los límites de los distritos o por la diferencia entre métodos de recuento en el nivel local, con lo cual el análisis geográfico de las elecciones en esta escala suele ser completado (McPhail, 1971). Sin embargo, los cambios recientes en tecnología, particularmente en los Sistemas de Información Geográfica (SIG), y la creciente disponibilidad de datos digitalizados vía Internet han facilitado los estudios a nivel del 
distrito electoral o equivalentes. De manera similar, con los avances en la difusión de los datos censales ligados a datos SIG georeferenciados, pueden desarrollarse análisis electorales a un nivel de agregación más local (Weichelt \& Zeitler, 2012). Aunque se ha argumentado que el empiricismo rampante habría lastrado el desarrollo de la geografía electoral convirtiéndola en una subdisciplina dominada, la disponibilidad de datos espaciales y los avances en tecnologías geoespaciales ha dado a la geografía electoral algunas herramientas clave para explicar resultados electorales y para mejorar modelos predictivos. Tres buenos ejemplos de esto serían los análisis factoriales, la autocorrelación espacial y el "retardo espacial" (spatial lag). Aunque estas ideas ya han sido usadas en el pasado, la disponibilidad de datos, la mejora en la velocidad de los ordenadores, y el creciente uso de tecnologías de acceso abierto suministran análisis de patrones electorales más completos que pueden ser de ayuda no sólo para la geografia sino para todas las disciplinas que trabajan con elecciones. Utilizando una aproximación estadística espacial, este análisis enfatizará los avances en tecnologías geoespaciales para comprender los patrones electorales del voto hispano en las recientes elecciones de los Estados Unidos.

Sin embargo, un análisis de los patrones actuales requiere una breve perspectiva histórica. Los resultados electorales de las presidenciales de 2008 mostraban un cambio racial y étnico respecto a los paisajes electorales previos en los Estados Unidos, caso de las elecciones de 2000 y 2004. Con una recesión económica en ciernes, un colapso del mercado inmobiliario y dos guerras en marcha, en los Estados Unidos en 2008 se alcanzaron unas cifras de votantes $(56,85 \%$ de la población en edad de votar) no vistas desde las elecciones presidenciales de 1968 (60,8\%) (GMU, 2010). Con la afluencia de votantes, Barack Obama, comparado con sus predecesores demócratas, fue capaz de ganar los estados de Ohio y Florida y de conseguir victorias en los estados tradicionalmente republicanos de Indiana, Carolina del Norte, Nevada, Colorado y Virginia. Debido a la presencia del primer candidato afroamericano viable, la cobertura mediática se centró en cubrir el apoyo de los afroamericanos a Obama. De acuerdo a las encuestas a pie de urna de la CNN, el 95 por ciento de los afroamericanos votaron por Obama en 2008 (CNN, 2008), lo que supone un incremento del 7 por ciento respecto a 2004 (CNN, 2004). Los votos afroamericanos fueron cruciales en la victoria de Obama en Virginia y Carolina del Norte. Sin embargo, como porcentaje total de votos, los votantes blancos sólo se incrementaron en torno a un 2 por ciento (del 41 por ciento en 2004 al 43 por ciento en 2008) (Lopez, 2009; CNN, 2004).

Como venía ocurriendo desde 1992, los medios aumentaron su cobertura de los votantes de las comunidades hispanas. Siendo la minoría de población más amplia en los Estados Unidos (13,5\%), el voto hispano ha sido muy buscado por los dos partidos políticos mayoritarios; de hecho, el aumento en apoyo hispano a George Bush en 2004 y el fuerte apoyo a Hillary Clinton en las primarias demócratas suministró contenidos interesantes para varios medios de comunicación respecto al voto de noviembre de 2008. Según las encuestas de la CNN, los votos hispanos aumentaron de un 53 por ciento a un 67 por ciento en 2008. Y según Hugo Lopez, los votantes hispanos se incrementaron de un 8 por ciento del electorado total a más de un 9 por ciento en 2008. Estados como Colorado y Nevada tuvieron un incremento del 5 por ciento en cuatro años, mientras en Nuevo México fue del 9 por ciento. Estos estados fueron fuertemente disputados y cambiaron sus votos electorales respecto a 2004 
(Lopez, 2009). Estas tendencias continuaron hasta 2012, lo que hacía pertinente preguntarse si continuarían así de cara a las presidenciales de 2016. En 2016, según el Censo de los Estados Unidos, la población hispana supondría cerca del 17,13 por ciento de la población, según la American Community Survey (ACS) de 2015 (U. S. Census Bureau, 2016).

La Figura 1 identifica claramente las concentraciones de hispanos en Estados Unidos, siendo mayores a lo largo de la frontera con México y muy significativas en las ciudades más grandes de todo el país; respecto a las elecciones presidenciales de 2016, el crecimiento de la población hispana parecía favorecer a los demócratas. Esta confianza aumentó el 16 de Junio de 2015, cuando el entonces candidato republicano Donald Trump profería su primer ataque a inmigrantes durante el anuncio de su candidatura presidencial: "Cuando México envía a su gente, no envían lo mejor... envían personas con muchos problemas, $\mathrm{y}$ traen sus problemas con ellas. Traen drogas. Traen crimen. Son violadores. Y algunos, asumo, son buenas personas" (cit. en Lee, 2015). En una línea de pensamiento similar, Trump proclamaría más tarde que, si resultaba elegido, "construiría un muro" que pagaría México, manteniendo así a los inmigrantes fuera de los Estados Unidos protegiendo los trabajos estadounidenses. Pensando en esta retórica, los demócratas eran cautelosos pero optimistas con respecto a que el voto latino alcanzaría cifras récord. Las encuestas de finales de septiembre mostraban empates relativos en Arizona y una desviación reducida en Texas, reforzada por un fuerte apoyo hispano. Finalmente, los demócratas asistieron a resultados mixtos. De acuerdo a Pew Research, en comparación con 2012, 4 millones de hispanos más se habían registraron para votar, aumentando las cifras a 27,3 millones. Estos incrementos eran mayores en los estados en disputa (battleground states) de Florida, Nevada y Arizona, aunque sólo en uno de ellos (Nevada) ganó Clinton. Los sondeos a pie de urna sugerían que un 66 por ciento del voto hispano apoyaban a Clinton, es decir, sólo un 1 por ciento menos respecto al 2008, pero un 5 por ciento menos del reciente crecimiento respecto a Obama en 2012 (Pew, 2016).

Si bien es un recurso importante, las encuestas a pie de urna sólo extraen tendencias generales en grandes áreas geográficas. En este tipo de encuestas, los diferentes grupos sociales son usualmente convertidos en un grupo homogéneo, y los votantes hispanos han sido así proyectados incluso más que otros grupos. De hecho, el estudio del comportamiento electoral de los hispanos es comparativamente mucho menor que el de otras minorías en Estados Unidos, y buena parte de la bibliografía les atribuye expresiones uniformes de creencias políticas comunes a una por lo demás heterogénea población (DeSipio, 1996). Arvizu \& Garcia (1996) sugieren que este problema se debería a su amplia distribución geográfica, que reduciría su impacto colectivo en los resultados electorales, que habría debilitado la percepción del rol de los hispanos en el sistema político.

Un estudio reciente de veintinueve libros de texto de introducción a la ciencia política usados en las universidades de todo el país mostraba que en veinte de esos libros menos del 1 por ciento de sus páginas estaban dedicadas a cuestiones políticas relacionadas con la comunidad hispana; de hecho, el mayor porcentaje era 3,5 por ciento en uno de esos manuales (Jaschik, 2010). El autor del informe argumentaba que "la contribución de los/as hispanos/as al desarrollo político de los Estados Unidos es un tema mayoritariamente ignorado" (Jaschik, 2010). Más allá de los libros de texto, las investigaciones más recientes sobre los patrones de voto de la 
comunidad hispana han adoptado una perspectiva regional. Es decir, estos estudios han identificado distribuciones regionales distintivas de las poblaciones hispanas políticamente activas (Bean \& Tienda, 1987; Boswell \& Jones, 1980; De la Garza et al., 1992; Falcón et al., 1991; Welch \& Hibbing, 1984; Arreola, 2002; Ehsan, 2017).

Figura 1. Porcentajes de población hispana por condado, Estados Unidos (2015)

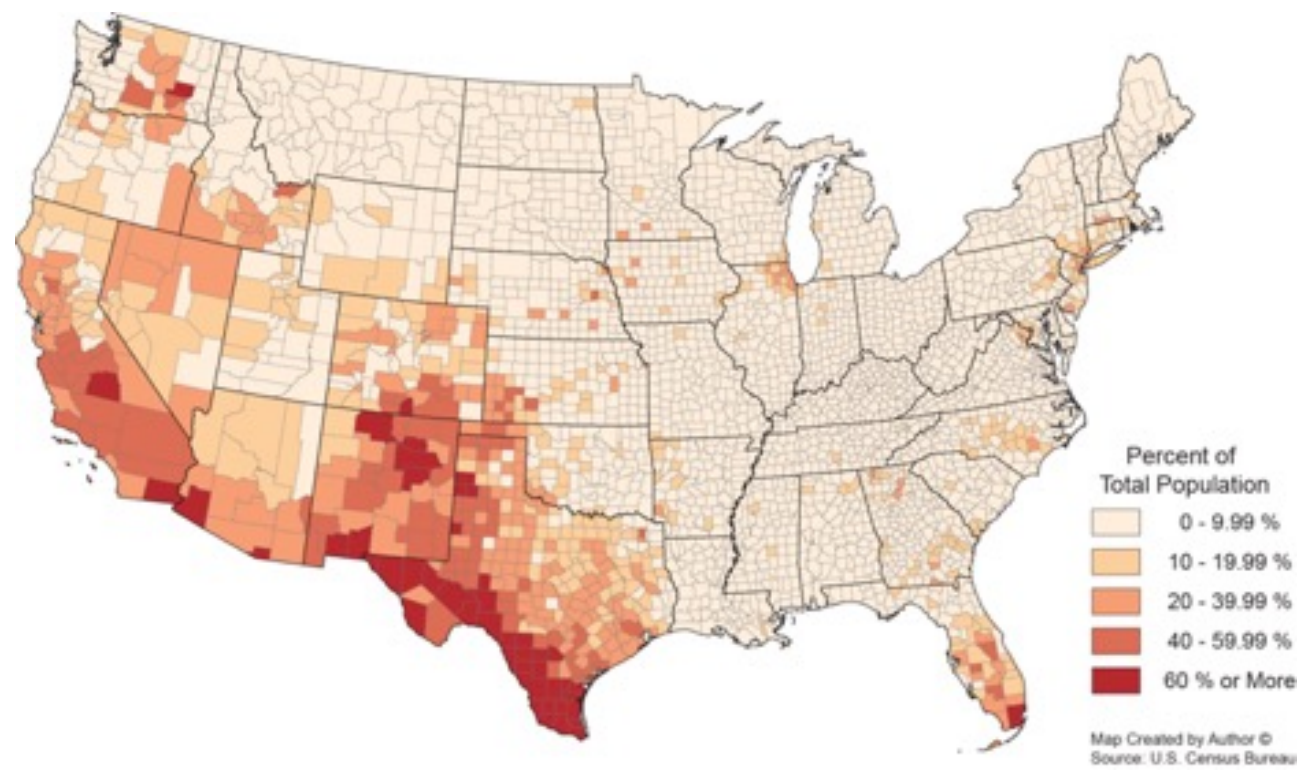

Fuente: Elaboración propia.

Para reafirmar estos estudios regionales con datos recientes del censo estadounidense (U. S. Census Bureau, 2016), hemos representado en la Figura 2 la mayor población hispana por condado en los Estados Unidos. Claramente el mayor grupo hispano lo conforman personas con ascendencia mexicana (63\%). El segundo grupo más grande, de origen puertorriqueño $(9,5 \%)$, se concentra en la ciudad de Nueva York y otras áreas metropolitanas del noreste del país, así como en el centro de Florida. La población cubana, el tercer grupo en términos numéricos $(3,7 \%)$, se localiza en el sur de Florida, fundamentalmente en Miami. Fuera de estos enclaves, miembros de estos grupos junto con otros provenientes de la República Dominicana, Centroamérica y Sudamérica se concentrarían mayoritariamente en California, Texas, Florida, Nueva York e Illinois. Esta distribución geográfica a través del país podría atribuirse a historias singulares, inmigración, economía y proximidad al país de origen (Arvizu \& Garcia, 1996; Torres, 1988; J. A. Garcia \& Arce, 1988; McClain \& J. A. Garcia, 1993; Arreola, 2002). Charles Kamaski lo plantea de la siguiente manera:

Hay 25 subgrupos hispanos diferentes identificados en el censo. Incluso si tomas los cuatro más grandes, esto es, mexicanos/as, salvadoreños/as, puertorriqueños/as y cubanos/as, tienen orígenes muy diferentes y muy diferentes culturas en algunas cosas y muchas similitudes, pero también muchas diferencias. Si combinamos eso con la cuestión de la inmigración o con la cuestión generacional [...] dentro de la 
comunidad mexicana-americana. Tenemos personas cuyas familias llevan cientos de años en los Estados Unidos, y en la misma comunidad, personas que cruzaron la frontera andando o volaron aquí ayer. Lo mismo ocurre con los puertorriqueños. Hay personas que llevan aquí mucho tiempo y personas que están justamente llegando desde la isla. De hecho, hay personas que nacieron aquí, crecieron en Puerto Rico y están de regreso. Conoces el desafío. Los cubanos son un poco diferentes, aunque hay más diversidad en esa comunidad de lo que algunos podrían pensar (cit. en Rodriguez, 2002: 116).

Estas diferencias culturales y geográficas se traducen en actitudes políticas diferentes sobre cuestiones políticas clave como la inmigración, la política exterior o los servicios sociales.

Figura 2. Principales subgrupos de la comunidad hispana a escala condado, Estados Unidos (2015)

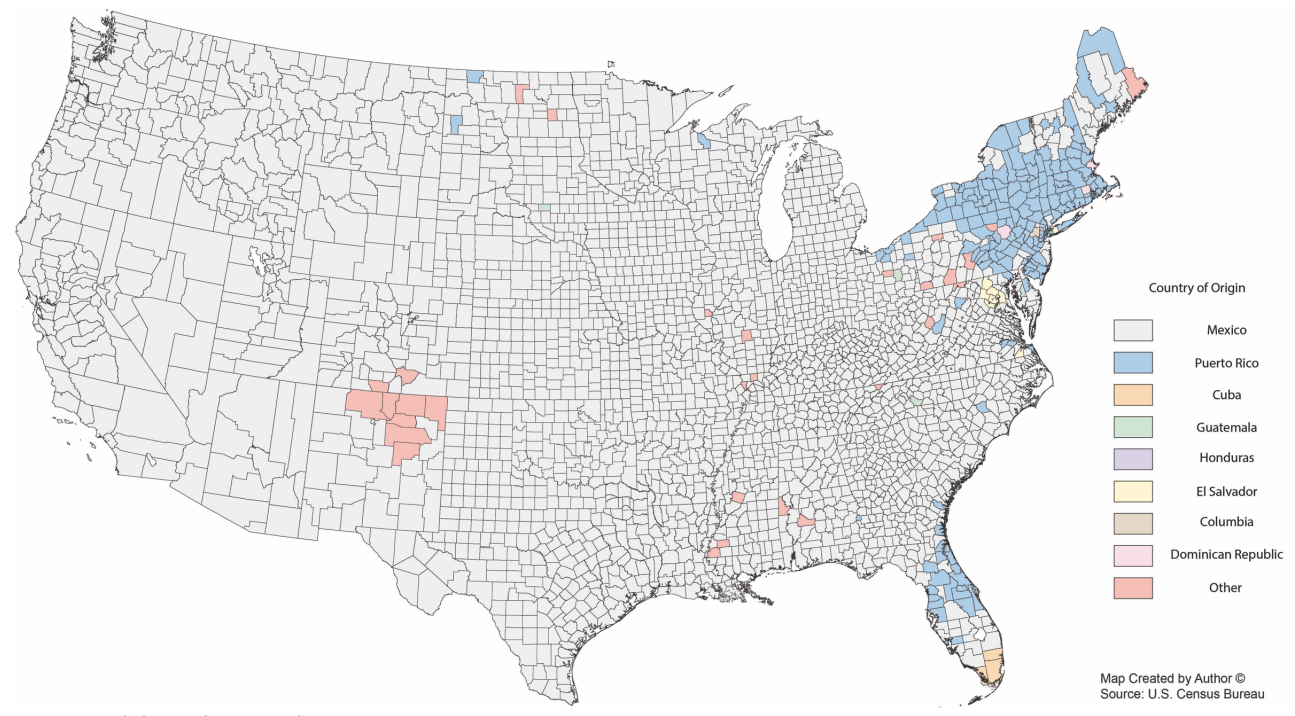

Fuente: Elaboración propia.

Debido a los diversos patrones de agrupación espacial entre los grupos hispanos del país, Classen (2004) sugiere que no hay una experiencia "hispana" unitaria como tal, sino que hay experiencias "mexicanas", "cubanas", "puertorriqueñas", etc., argumento reforzado con los resultados del Latino National Political Survey (LNPS). El LNPS se realizó en los años 1980 para apreciar las percepciones políticas de los grupos con orígenes hispanos. Proclamado como el mayor cuestionario en torno a las creencias políticas hispanas, los analistas del LPNS concluyeron que existen suficientes diferencias entre mexicanos, puertorriqueños y cubanos como para estudiarlos por separado (Uhlaner et al., 1989). Este informe preguntaba a los encuestados/as sobre ideología, afiliación partidaria y cooperación política entre grupos, por mencionar algunas categorías. Respecto a la ideología, los mexicanos/as eran más proclives a definirse como liberales, seguido por puertorriqueños/as, y después cubanos/as. En términos de votos, los/as mexicanos/as se inclinaban más por los 
demócratas que puertorriqueños/as o cubanos/as, siendo precisamente la comunidad cubana la de menor apoyo a los demócratas. Otra cuestión interesante se refería a cómo los encuestados se percibían respecto a otros grupos hispanos: el consenso era que la totalidad de los tres grupos se sentían más próximos a los blancos que a los otros grupos de la comunidad hispana. Una cuestión final preguntaba si creían que su grupo tenía preocupaciones políticas similares a las de los otros hispanos, cuestión que era mayoritariamente respondida de forma negativa. Y, de forma muy significativa, cuando fueron encuestados sobre temas más sociales (educación, crimen, drogas, etc.), la mayoría de los grupos creían que el gobierno federal debería de hacer más, incluso si ello significaba una subida de impuestos (Rodriguez, 2002). Es más, De la Garza et al. afirman que "en particular entre ciudadanos (regularizados), el LNPS ilustra que los mexicanos, puertorriqueños y cubanos tienen mucho en común, pero también difieren de forma significativa en cuestiones importantes" (1992: 13).

Mientras que las investigaciones sobre comportamiento electoral indica que las diferencias regionales y culturales entre hispanos existen, pocos trabajos han examinado espacialmente las diferencias interregionales entre esos grupos entre regiones. Shaw et al. (2000), que trabajaron con los resultados de tres encuestas realizadas en la comunidad hispana de los estados de Texas, California y Florida en relación a los resultados electorales, han sido los únicos en realizar un estudio espacial. Desgraciadamente, el estudio estaba plagado de errores de respuesta por parte de la muestra encuestada, ya que encontraron lo siguiente:

El 77 por ciento de los ciudadanos latinos con edad de votar decían que estaban registrados para las elecciones generales de noviembre de 1996, con un 86 por ciento afirmando que habían votado (un 67 por ciento del total). De acuerdo con los registros de los condados, solo un 46 por ciento de los encuestados estaban realmente registrados, mientras que votaron realmente el 77 por ciento de los registrados, lo que dejaría el electorado validado (votantes confirmados/todos elegibles) en un 31 por ciento (Shaw et al., 2000: 341).

Debido a las complejidades de estudiar las tendencias del voto hispano, las tecnologías geoespaciales y las estadísticas espaciales suministran aproximaciones excepcionales para estudiar tendencias de voto de grupos específicos en el paisaje electoral. En las secciones que siguen se identificarán tres técnicas distintas de geografía electoral para revelar eras electorales, para identificar el agrupamiento espacial de las variables clave, y finalmente para fortalecer estadísticamente los métodos tradicionales frecuentemente utilizados de forma incorrecta por no geógrafos.

\section{Análisis factorial modo $\mathrm{T}$ ( $T$-mode) y modo $\mathrm{S}$ ( $S$-mode)}

Se ha comparado el análisis espacial con una expedición de pesca en la que el objetivo es reducir una amplia red de datos a un formato comprensible (Kim \& Mueller, 1978; Tabachnick \& Fidell, 2007). El análisis factorial es una técnica que examina matrices enteras de correlaciones de forma simultánea, reduciendo las grandes matrices a una matriz más pequeña y más manejable de similitudes entre las elecciones observadas y un número limitado de factores (Shelley et al., 1996). Estos factores se 
interpretan entonces como identificativos de las pautas de elección más distintivas y representativas para un período de estudio (Archer \& Taylor, 1981).

Aplicaremos el análisis factorial modo-T o "modo temporal" para el área de estudio y para todas las elecciones presidenciales celebradas entre 1980 y $2016 . \mathrm{La}$ elección de 1980 como fecha inicial fue hecha porque fue el primer año que el Censo de Estados Unidos utilizó una metodología común de autoregistro para identificar a las personas como hispanas. El análisis factorial modo-T implica comprender las correlaciones de las elecciones en los espacios de los condados y en el tiempo, lo que a su vez agrupa las elecciones en base a una geografía similar y apoyo partidista (Shelley \& Archer, 1989). Estos grupos entonces indican si unas elecciones específicas son elecciones normales o críticas, de realineamiento (Archer \& Shelley, 1986). Como las eras electorales son identificadas para áreas específicas, se puede llevar a cabo una investigación espacial adicional utilizando el análisis factorial modo-S.

El análisis factorial modo-S o "modo espacial" implica analizar las relaciones entre las unidades de observación a lo largo del tiempo. Específicamente, el análisis factorial modo-S "agrupa las áreas de investigación en regiones electorales mediante el análisis de matrices de correlaciones electorales entre áreas a lo largo de diferentes procesos electorales. Cada región se compone de lugares con trayectorias electorales similares a lo largo del tiempo" (Shelley et al., 1996: 282-283). Una vez identificadas estas regiones, una muestra de los tres condados con las mayores cargas factoriales nos proporcionaría evidencias sobre los patrones electorales de esas regiones en un período de tiempo determinado. Este estudio se conectaría así con un trabajo anterior realizado por el autor (Weichelt, 2008) en el que se realizaba un análisis detallado de todos los condados de EE UU y otro en los condados donde el porcentaje de aumento de la población hispana fuese de hasta un 40 por ciento. Este estudio mostraba que los resultados eran consistentes en los condados con el 20 por ciento de la población total hispana o más. Como proponíamos anteriormente, y con la población hispana aumentando significativamente en 2016, realizaremos un análisis factorial en modo-T para todos los condados en los EE UU que se contrastará con un análisis en modo-T para los condados con poblaciones hispanas del 20 por ciento o más. Una vez identificadas las eras electorales del modo-T en los condados con un 20 por ciento o más, un nuevo análisis del modo $\mathrm{S}$ identificará las trayectorias electorales específicas en los condados del área de estudio.

En la Tabla 1 vemos los resultados del análisis factorial en modo-T para todos los condados estadounidenses en todas las elecciones presidenciales de 1980 a 2016, así como para todos los condados con poblaciones hispanas del 20 por ciento o más. Debido a los análisis que realizaremos más adelante, la conectividad geográfica de los condados es importante, por lo que Hawaii y Alaska fueron excluidos de esta investigación. Como muestra claramente la Tabla 1, las eras electorales difieren en función de las proporciones crecientes de población hispana que incluyamos en el análisis. El análisis en modo-T para los condados de estudio $(3,106)$ muestra dos épocas distintas que explicarían el 90,14 por ciento de la varianza para todos los condados. Los condados de Broomfield (Colorado) y Bedford City (Virginia) se eliminaron de la investigación debido a inconsistencias en los datos entre 1980 y 2016.

En general, los puntajes de 0,70 o más para los años electorales en la matriz de componentes rotados se correlacionan con eras específicas. Las elecciones realizadas entre 1980 y 1996 indican que los resultados a nivel de condado se mantuvieron 
bastante consistentes. Las elecciones de 2000 no recibieron puntaje de 0,70 para ninguna era, lo que indica que esta elección se desvió de los patrones de "votación normal" de la era electoral anterior y avanzó los de la siguiente, que empezaría en 2004.

Tabla 1. Eras electorales para todos los condados de Estados Unidos y para aquellos con una población hispana del $20 \%$ o más

\begin{tabular}{|l|c|c|c|c|c|}
\hline \multicolumn{2}{|c|}{$\begin{array}{c}\text { Análisis factorial modo T de todos los } \\
\text { condados de EE UU }\end{array}$} & \multicolumn{3}{c|}{$\begin{array}{c}\text { Análisis factorial modo T de los condados con } \\
\text { un 20\% o más de población hispana }\end{array}$} \\
\hline & Matriz de componentes rotados & & \multicolumn{2}{c|}{ Matriz de componentes rotados } \\
\hline & 1 & 2 & & 1 & 2 \\
\hline 2016 & 0,201 & 0,924 & 2016 & 0,948 & 0,239 \\
\hline 2012 & 0,276 & 0,934 & 2012 & 0,941 & 0,310 \\
\hline 2008 & 0,292 & 0,935 & 2008 & 0,931 & 0,322 \\
\hline 2004 & 0,465 & 0,817 & 2004 & 0,865 & 0,351 \\
\hline 2000 & 0,666 & 0,696 & 2000 & 0,827 & 0,532 \\
\hline 1996 & 0,800 & 0,547 & 1996 & 0,653 & 0,728 \\
\hline 1992 & 0,887 & 0,377 & 1992 & 0,584 & 0,789 \\
\hline 1988 & 0,812 & 0,372 & 1988 & 0,403 & 0,875 \\
\hline 1984 & 0,879 & 0,394 & 1984 & 0,486 & 0,851 \\
\hline 1980 & 0,894 & 0,053 & 1980 & 0,091 & 0,935 \\
\hline
\end{tabular}

Fuente: Elaboración propia.

Se identificaron 365 condados con 20 por ciento o más de población hispana. Los resultados del análisis factorial modo-T también revelaron dos eras (que explicarían el 94,34 por ciento de la varianza), pero en comparación con el análisis de los condados continentales (esto es, sin los estados de Hawaii ni Alaska), estos 365 condados mostraban eras electorales distintas. Como se afirmaba con anterioridad, las elecciones de 1992 y 1996 a menudo se definen como históricas para el voto hispano. La Tabla 1 lo indica claramente, al identificar una primera era, que iría desde 1980 hasta 1996, y una segunda, de 2000 hasta 2016. A medida que las proporciones de población hispana aumentaba en estos condados, las elecciones de 2000 mostraban los resultados electorales cambiantes a nivel condado. Si bien el análisis en modo-T simplemente identifica patrones de votación similares a nivel condado, el análisis en modo-S proporciona un contexto espacial para los resultados electorales. El análisis en modo-S realizado para esta investigación se completará para los 365 condados con poblaciones hispanas del 20 por ciento o más con un análisis de la era electoral más reciente, que como vimos en la Tabla 1 abarcaría de 2000 a 2016.

El análisis factorial en modo-S para las cinco elecciones presidenciales produjo tres trayectorias electorales distintas, que explicarían el 86,12 por ciento de la varianza. El grupo 1, el grupo más grande ( 240 condados) se caracteriza por un declive general en el voto demócrata durante la era electoral. Podemos representar gráficamente los condados con mayores cargas factoriales para mostrar la trayectoria general de votación de los condados de cada grupo como un todo. De hecho, la Figura 3 es un gráfico de líneas con tres condados del Grupo 1, que muestra una disminución general del apoyo demócrata durante las elecciones de 2000 a 2016. El Grupo 2 muestra un aumento general del apoyo demócrata, con la excepción de 2012, como se puede ver en la Figura 4. Y el grupo final, el 3, muestra un apoyo fluctuante hasta las elecciones de 2008, seguido por un declive general en el apoyo demócrata en 2016 (ver Figura 5). 
Figura 3. Grupo 1 - Apoyo Demócrata en disminución

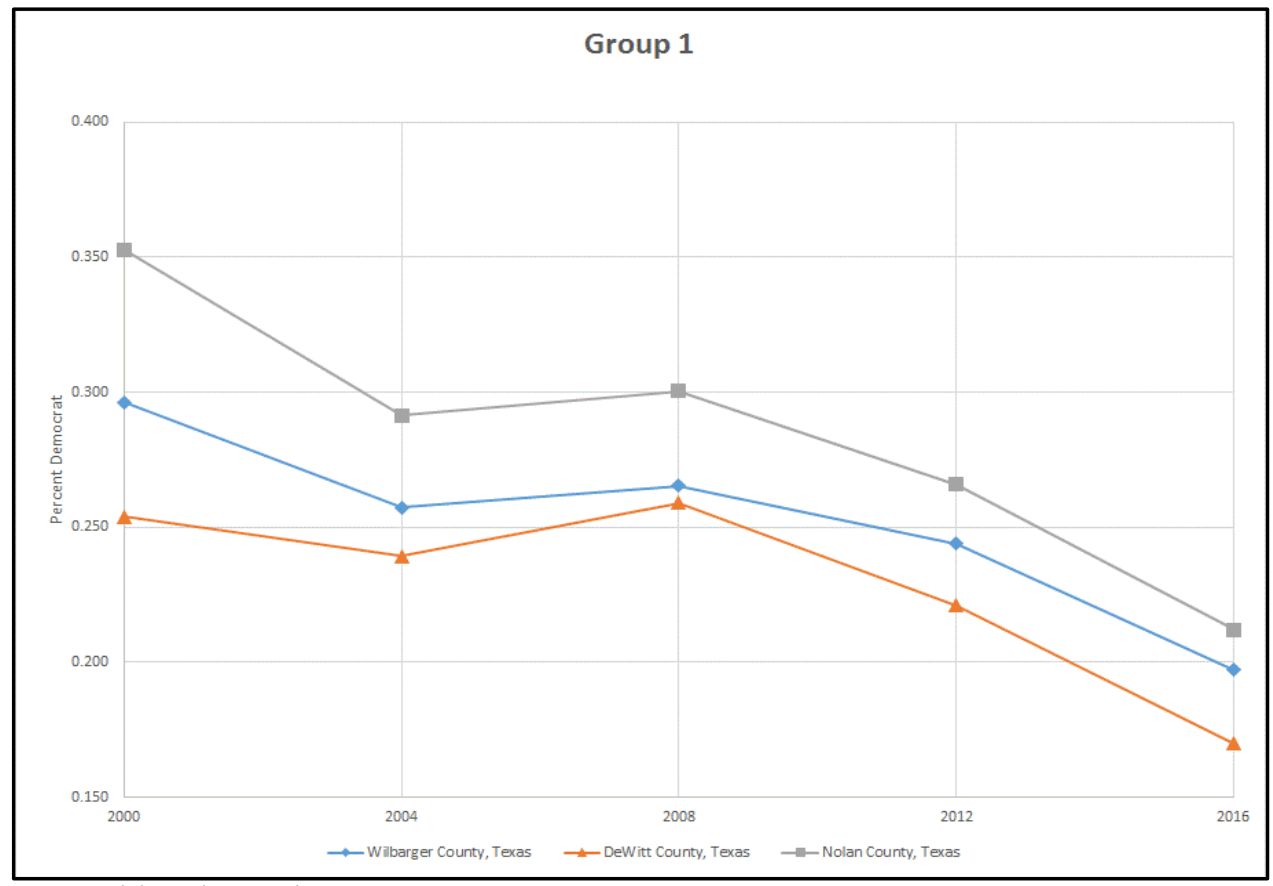

Fuente: Elaboración propia.

Figura 4. Grupo 2 - Apoyo Demócrata en aumento

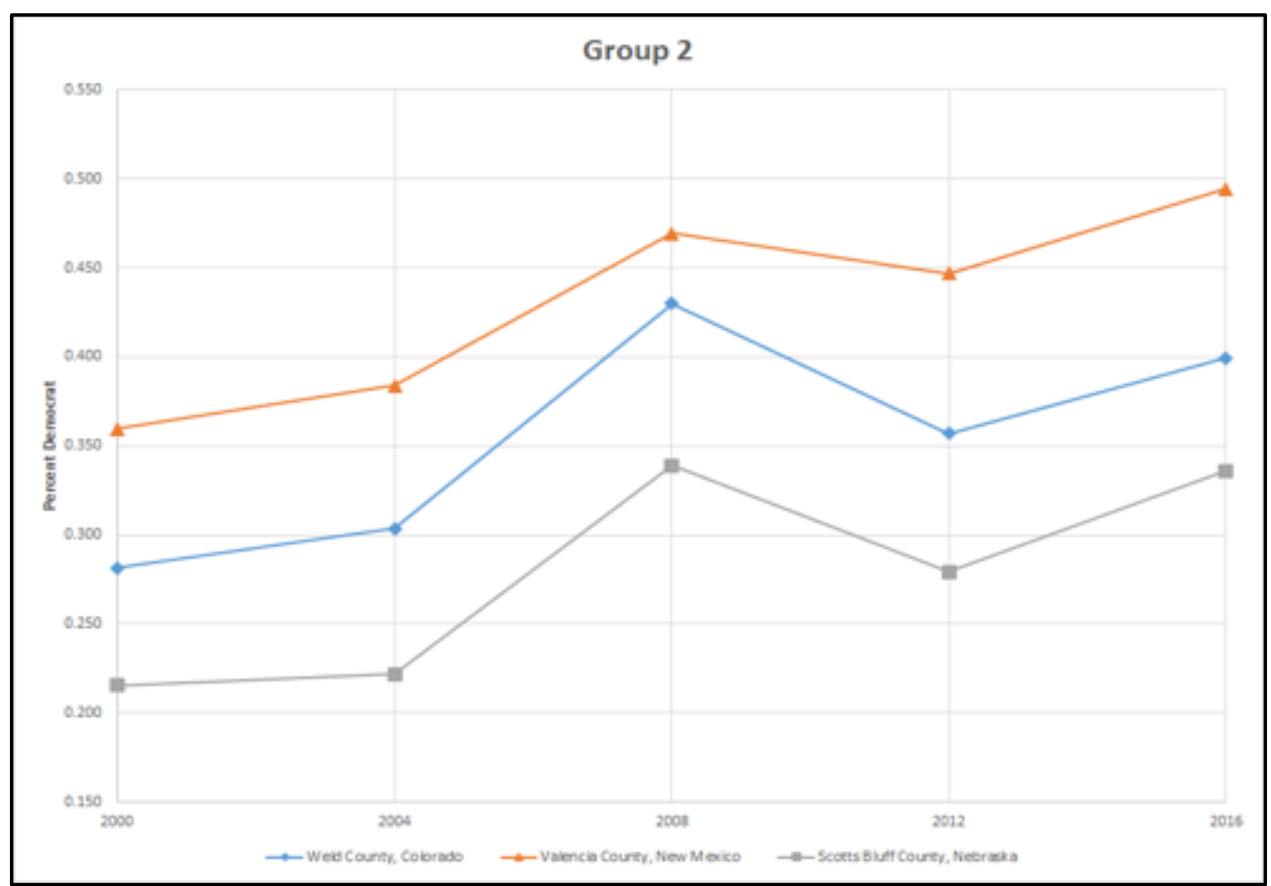

Fuente: Elaboración propia. 
Figura 5. Grupo 3 -Apoyo Demócrata fluctuante

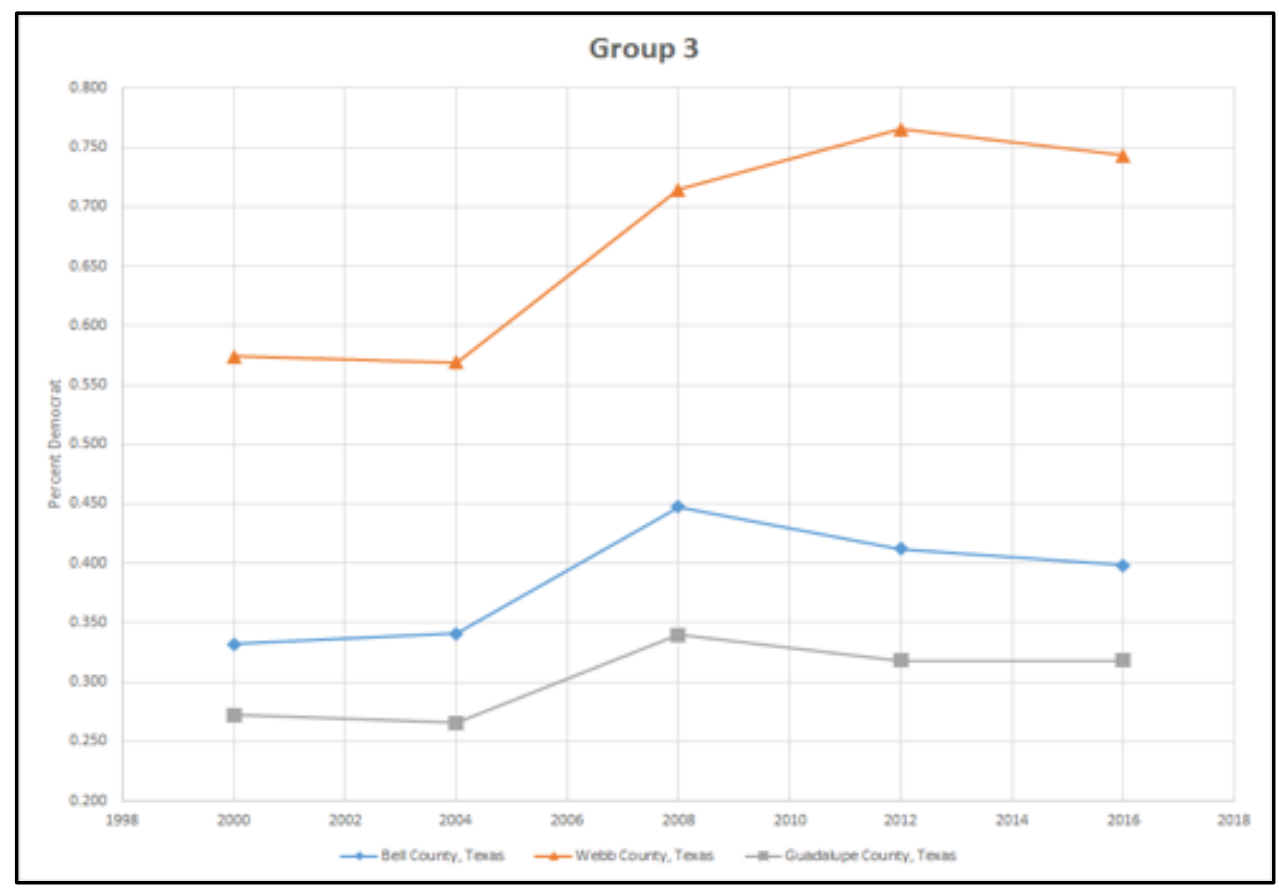

Fuente: Elaboración propia.

Debido a la naturaleza espacial del análisis factorial modo-S, estos grupos pueden ser cartografiados. De hecho, la Figura 6 nos proporciona una lectura espacial de esos grupos para todos los condados en los Estados Unidos con población hispana del 20 por ciento o más, ilustrando claramente un patrón espacial de resultados muy específico.

El aumento del apoyo demócrata (Grupo 2) es más fuerte en los condados de Nuevo México, Arizona, norte de Nevada y este de Washington, condados que también tienden a concentrar la mayor población hispana de los 365 condados de la Figura 1. En las recientes elecciones presidenciales, Nuevo México, Colorado y Nevada fueron considerados como contendientes demócratas (democratic contenders), al tiempo que seguían siendo "estados en disputa" (battleground states). Estos resultados electorales se han visto favorecidos tanto por el aumento de la población hispana como por su participación electoral. Los condados del Grupo 1, donde el apoyo a los demócratas ha ido en descenso, tienden a tener las proporciones más bajas de poblaciones hispanas y se encuentran, en la mayoría de los casos, en condados tradicionalmente rurales, con la excepción de la costa oeste de California. De hecho, una investigación previa en los condados de Texas mantiene que mientras la población hispana aumenta en la mayoría de los condados del Grupo 1, es muy probable que muchos sean o bien trabajadores temporales o bien personas indocumentadas que trabajan en actividades económicas primarias o secundarias, y es poco probable que participen en elecciones (Weichelt, 2010). Si bien esto no se cumple en todos 
los condados, las localizaciones de los del Grupo 1 apoyarían este supuesto. Finalmente, los condados del Grupo 3 (donde fluctúa el apoyo a los Demócratas), aunque están agrupados en ciertas zonas del país, muy probablemente estén influenciados por los cambios en el apoyo que han afectado a todos los votantes de cada uno de los condados.

Figura 6. Resultados del análisis factorial modo-S para los tres grupos electorales identificados

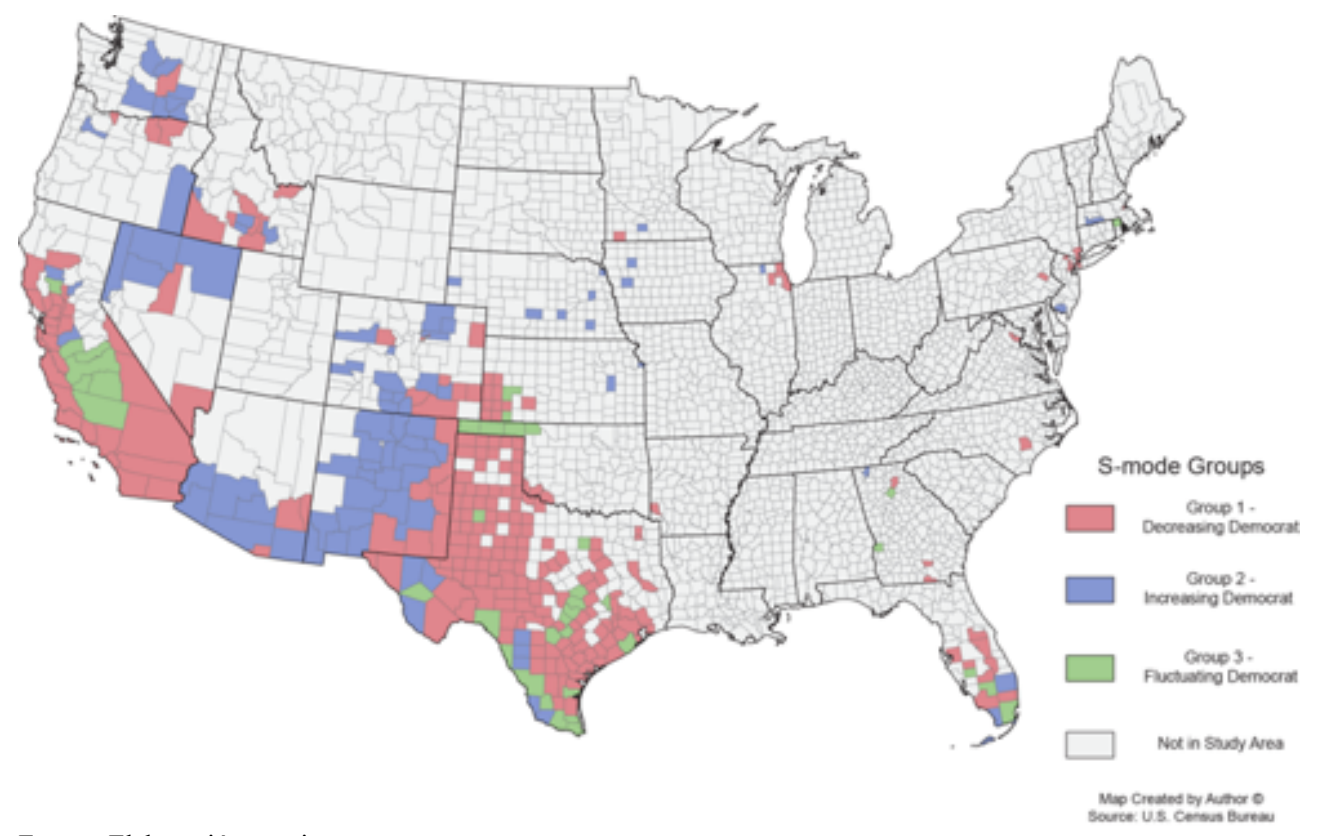

Fuente: Elaboración propia.

Usados de manera conjunta, tanto el análisis modo-T como el modo-S evidencian que los condados con mayores proporciones de población hispana muestran patrones electorales diferenciados. Estos resultados respaldan el hecho de que tratar a la comunidad hispana como un grupo homogéneo puede llevar a interpretaciones erróneas sobre su impacto en los resultados electorales. Una vez hemos identificado las pautas espaciales, podemos recurrir a otras metodologías para comprender cómo votaron los distintos grupos. En última instancia, combinar el análisis espacial y la teoría política nos suministrará un análisis electoral más sólido de cualquier grupo.

\section{Regresión espacial}

Si bien los análisis en modo-T y en modo-S son válidos para identificar las eras electorales y las variaciones espaciales de las trayectorias de votación, podemos recurrir a técnicas geoespaciales adicionales para proporcionar una mayor comprensión de los patrones de voto. El análisis de regresión tradicional proporciona 
evidencias en torno a la influencia de variables independientes en la variable dependiente, y la validez de los contrastes de hipótesis estadísticas se basa en la premisa de que los datos son aleatorios y de que los errores de muestreo parten de una distribución normal. Debido a la naturaleza espacial de los datos electorales, ni los datos son aleatorios ni se ajustan a una distribución normal. Para explicar esta cuestión, Waldo Tobler creó la "primera ley de la geografía" que establece que "todo se relaciona con todo, pero las cosas cercanas están más relacionadas que las cosas distantes" (Tobler, 1970: 236). En 1969, Cliff \& Ord (1969) denominaban a este fenómeno autocorrelación espacial. Creían que "el caso especial de correlación en el espacio, cuando existe una relación entre unidades espaciales cercanas de la misma variable, necesita ser identificado si queremos contestar las preguntas de investigación con precisión" (Getis, 2007: 492). Cliff \& Ord se dieron cuenta de que esto podría ser un problema en el análisis de datos espacialmente autocorrelacionados. Como explica Getis:

Nos mostraron lo que se conoce por error de especificación en el análisis espacial, esto es, que los modelos que requerían estadísticas tradicionales para ser evaluados se especificaban de forma incorrecta si no se tenía en cuenta la autocorrelación espacial cuando los datos se georreferenciaban. Hasta el día de hoy, muchos economistas no saben que para que un modelo de mínimos cuadrados ordinarios (MCO) se especifique adecuadamente, los residuos deben ser espacialmente independientes en la región de estudio asignada (Getis, 2007: 493).

Si bien existen varios procedimientos estadísticos para contrastar la autocorrelación espacial (por ejemplo, la I de Moran, la C de Geary y la K de Ripley), nuestro análisis se concentrará en el uso del I de Moran, que es un coeficiente de correlación ponderado utilizado para detectar desviaciones de la aleatoriedad espacial. Estas desviaciones indicarían patrones espaciales, como, por ejemplo, conglomerados (clusters).

El índice I de Moran prueba la autocorrelación espacial global en datos a nivel grupal. La autocorrelación espacial positiva significa que las áreas cercanas tienen similares porcentajes, lo que indica una

agrupación espacial global. Las áreas cercanas tienen tasas similares cuando sus poblaciones y orientaciones son similares, por tanto, cuando las tasas en áreas cercanas son similares, la I de Moran será alta y positiva. Cuando las tasas son diferentes, la I de Moran será negativa (Moran, 1950: 17-19).

Si la autocorrelación espacial es detectada por el I de Moran, se puede ejecutar una regresión espacial para corregir los errores asociados con el análisis de regresión tradicional aplicado a los datos espaciales. Para completar una regresión espacial, podemos usar un paquete de software creado por el geógrafo Luc Anselin (2003) llamado GeoDa. Este software, que utiliza shapefiles, es un paquete de software libre y de código abierto. Una ventaja que proporciona GeoDa en comparación con otros paquetes estadísticos es la creación de pesos espaciales para un conjunto dado de datos; estos pesos se usan luego para obtener los resultados de la regresión espacial.

En este apartado de nuestra investigación recurriremos a un modelo de regresión espacial llamado el modelo de máxima verosimilitud del retardo espacial. El modelo de retardo espacial proporciona un peso espacial a la variable dependiente que puede 
usarse para depurar los resultados del análisis de los mínimos cuadrados ordinarios (MCO). El retardo espacial de una variable especificada se computa calculando el promedio ponderado de los polígonos circundantes. Por ejemplo: un tramo censal con tres extensiones vecinas que tenían 10,15 y 20 por ciento de población hispana tendría un retraso espacial del 15 por ciento. Esto crea una matriz de ponderaciones espaciales estandarizadas por filas que representa la tasa promedio de cada tramo vecino. Específicamente, se seleccionó un peso de continuidad tipo Rook para este análisis. La contigüidad tipo Rook selecciona pesos para polígonos solo con bordes comunes para definir adyacencia, y cuenta para todos los vecinos (Anselin, 2005).

La tendencia espacial a agruparse de los resultados electorales proporciona a los investigadores la oportunidad de utilizar este software geoespacial para identificar patrones, explicar tendencias, corregir la autocorrelación espacial y crear modelos predictivos más específicos para variables clave. Estos análisis no fueron posibles antes del advenimiento de las tecnologías geoespaciales. GeoDa, como software de código abierto, requiere un conocimiento limitado de SIG, pero es una poderosa herramienta para corregir la autocorrelación espacial que a menudo, si no se tiene en cuenta, produce resultados de mínimos cuadrados ordinarios poco confiables.

Utilizando un modelo de MCO a nivel de condados continentales, con el porcentaje de apoyo a demócratas como variable dependiente y el porcentaje de población hispana como variable independiente, los resultados indican que, a medida que aumenta la proporción de población hispana por condado, el porcentaje de apoyo a los demócratas también aumenta. La Tabla 2 muestra los resultados de MCO para este caso. Aunque existe una relación débil pero lineal entre las dos variables, el valor de R-cuadrado es muy débil (R-squared: 0,034551), por lo que cualquier análisis es relativamente problemático. Esta debilidad probablemente se deba a la gran variación tanto del apoyo demócrata como de la población hispana en los condados estadounidenses, lo que produce un alto nivel de error estadístico.

Tabla 2. Resultados de la regresión de mínimos cuadrados ordinarios (MCO)

R-squared: 0,034551

Adjusted R-squared: 0,034241

Sum squared residual: 69,6626

Sigma-square: 0,0224284

S.E. of regression: 0,149761

Sigma-square ML: 0,022414

S.E of regression ML: 0,149713
F-statistic: 111,158

Prob(F-statistic): 1,46927e-025

Log likelihood: 1492,14

Akaike info criterion: -2980,28

Schwarz criterion: $-2968,2$

\begin{tabular}{ccccc} 
Variable & Coefficient & Std.Error & t-Statistic & Probability \\
\hline CONSTANT & 0,296491 & 0,00320857 & 92,4061 & 0,00000 \\
PerHis15 & 0,208875 & 0,0198115 & 10,5431 & 0,00000 \\
\hline
\end{tabular}

Fuente: Elaboración propia.

Aunque el MCO se ve obstaculizado por patrones inconsistentes en los datos, en términos espaciales las zonas con mayores niveles de apoyo demócrata tienden a encontrarse en áreas con proporciones crecientes de población hispana (es decir, el sur de Texas, Nuevo México, Nevada y gran parte de California). Usando GeoDa para conducir un I de Moran tanto para el porcentaje de voto demócrata como para el porcentaje de población hispana por condado, ambas variables muestran un alto 
nivel de autocorrelación espacial. El porcentaje de voto demócrata tiene un I de Moran de 0,59 , mientras que el porcentaje de hispanos está aún más espacialmente agrupado, con un I de Moran de 0,80 . Debido a la aglomeración espacial de ambas variables, la bibliografía citada anteriormente (Anselin, 2005) nos muestra que un modelo de retraso espacial mejora significativamente los modelos MCO cuando identificamos la autocorrelación espacial a través de los altos valores del I de Moran. Este sería claramente el caso cuando se comparan los resultados del retraso espacial con los resultados del MCO de la Tabla 2.

Tabla 3. Resultados de la regresión con retardo espacial

\begin{tabular}{|c|c|c|c|c|}
\hline \multicolumn{2}{|l|}{$\begin{array}{l}\text { R-squared: } 0,559547 \\
\text { Sq. Correlation: N/A } \\
\text { Sigma-square: } 0,0102256 \\
\text { S.E of regression: } 0,101122\end{array}$} & \multicolumn{3}{|c|}{$\begin{array}{l}\text { Log likelihood: } 2483,02 \\
\text { Akaike info criterion: }-4960,03 \\
\text { Schwarz criterion: }-4941,91\end{array}$} \\
\hline Variable & Coefficient & Std.Error & z-value & Probability \\
\hline SpatialWeight_Dem16 & 0,764554 & 0,0137444 & 55,6265 & 0,00000 \\
\hline CONSTANT & 0,0647489 & 0,00447089 & 14,4823 & 0,00000 \\
\hline PerHis15 & 0,112145 & 0,0142899 & 7,84788 & 0,00000 \\
\hline
\end{tabular}

Fuente: Elaboración propia.

La Tabla 3 muestra un resultado mejorado en el modelo de retraso espacial predictivo en comparación con el MCO. El valor de R-cuadrado aumentó drásticamente de 0,03 a 0,55 en el modelo de retraso espacial. Aunque ningún modelo puede predecir con exactitud un resultado, la Tabla 3 muestra explícitamente la relación positiva entre el aumento de los porcentajes de población hispana y el aumento del voto al Partido Demócrata. Por lo tanto, nos encontramos ante un modelo predictivo más sólido si tratamos la autocorrelación espacial con el modelo de retardo espacial ${ }^{3}$.

\section{Conclusiones}

Las críticas realizadas en el pasado a la dependencia de la geografía electoral respecto a los datos empíricos están ciertamente fundadas, pero descartar la disciplina, en lugar de adoptar las tendencias actuales, sería desafortunado. De hecho, los datos empíricos siguen siendo fundamentales para cualquier estudio electoral. Si bien la teoría social ciertamente es necesaria para formular una sólida comprensión de las intenciones de voto, una colaboración entre el positivismo y la teoría social podría ser el mejor método para la investigación en este campo. Entiendo que la revolución geoespacial de principios de la década de 2000, combinada con las tendencias recientes de los Big Data, realza la posición de la geografía electoral en los estudios electorales. Aunque el objetivo de este texto era destacar cómo las tecnologías geoespaciales actuales pueden contribuir, esto no supone reemplazar o desacreditar las críticas anteriores. Más bien, este artículo ha resaltado las tendencias recientes en los

3 La traductora agradece a Javier Sánchez Carrión su ayuda en la traducción de los términos técnicos de este artículo. 
estudios electorales y añade nuevas técnicas para ayudar a los investigadores y al público a estudiar las elecciones.

Con la disponibilidad cada vez mayor de datos demográficos y tecnologías de código abierto, las investigaciones pueden filtrar datos a un volumen que no era posible hace quince años. Sin embargo, tanto los geógrafos electorales como los politólogos continúan en desacuerdo por cuestiones de inferencia ecológica. Los análisis factoriales modo-T y modo-S proporcionan una comprensión temporal y espacial del pionero trabajo de Key sobre las elecciones críticas. Si bien las eras se identifican en el modo-T, el modo-S puede identificar espacialmente áreas con trayectorias electorales similares. Estos resultados podrían mitigar las preocupaciones por la inferencia ecológica. Además, los métodos adicionales, como el retardo espacial, si no se utilizan para corregir la autocorrelación espacial, podrían invalidar otras prácticas comúnmente utilizadas, como el análisis de regresión tradicional. En general, estos enfoques se han mostrado útiles para analizar las comunidades hispanas y los resultados electorales del Partido Demócrata pero, si aplicamos métodos cualitativos adicionales como entrevistas y grupos focales, y recurrimos a la teoría social y política para ayudar a comprender los resultados, podremos obtener una comprensión mayor y matizada de por qué los individuos votaron de una forma u otra. Aquí es donde la geografía electoral, la teoría social y la ciencia política pueden y deben trabajar juntas para proporcionar resultados sólidos.

En conclusión, la tecnología y la disponibilidad de datos están cambiando el mundo. Los investigadores no deberían ignorar estas tendencias, especialmente en lo que se refiere a las elecciones. Los métodos de Nate Silver junto con la campaña de Obama ilustraron este punto visiblemente en 2008. Sin embargo, habría que mantener cierta prudencia. Si 2016 proporcionó alguna advertencia a los investigadores de Big Data, el exceso de confianza en los datos de los especialistas en encuestas predijo dos elecciones clave incorrectamente, tanto en el Reino Unido como en Estados Unidos. Sin embargo, en los Estados Unidos, la geografía fue vital para comprender la elección como un todo. Al final, todas las cartas deben ponerse sobre la mesa. La geografía debería reconocer las limitaciones del análisis espacial, mientras que la ciencia política debería estar al tanto de la creciente importancia de la geografía para comprender el panorama electoral. Esto requiere que los adversarios acepten las fortalezas de los demás a través del diálogo y la colaboración.

\section{Bibliografía}

Agnew, J. (1985) "Models of Spatial Variation in Political Expression: The Case of the Scottish of National Party”. International Political Science Review, vol. 6, núm. 2, 171-196.

Agnew, J. (1987) The United States in the World-Economy: A Regional Geography. Cambridge: Cambridge University Press.

Agnew, J. (1990) "From Political Methodology to Geographical Social Theory: A Critical Review of Electoral Geography, 1960-1987”, en R. J. Johnston, F. M. Shelley \& P. J. Taylor (eds.) Developments in Electoral Geography. London: Routledge, 15-21.

Agnew, J. (1996) "Mapping Politics: How Context Counts in Electoral Geography”. Political Geography, vol. 15, núm. 2, 129-146. 
Anselin, L. (2005) Exploring Spatial Data with GeoDa: A Workbook. Urbana-Champaign: Spatial Analysis Laboratory, Department of Geography, University of Illinois, UrbanaChampaign.

Archer, J. C. \& Shelley, F. M. (1986) American Electoral Mosaics. Washington, D.C.: Association of American Geographers.

Archer, J. C. \& Taylor, P. J. (1981) Section and Party: A Political Geography of American Presidential Elections from Andrew Jackson to Ronald Regan. Chichester: John Wiley.

Arreola, D. (2002) Tejano South Texas. Austin: University of Texas Press.

Arvizu, J. R. \& Garcia, C. F. (1996) "Latino Voting Participation: Explaining and Differentiating Latino Voting Turnout Out”. Hispanic Journal of Behavioral Sciences, vol. 18, núm. 2, 104-128.

Baybeck, B. \& McClurg, S. D. (2005) "What Do They Know and How Do They Know It? An Examination of Citizen Awareness of Context". American Politics Research, vol. 33, núm. 4, 492-520.

Bean, F. D. \& Tienda, M. (1987) The Hispanic Population of the United States. New York: Russell Sage Foundation.

Boswell, T. D. \& Jones, T. C. (1980) “A Regionalization of Mexican Americans in the United States”. Geographical Review, vol. 70, núm. 1, 88-98.

Brunn, S. D. (1974) Geography and Politics in America. New York: Harper and Row.

Cliff, A. D. \& Ord, J. K. (1969) "The problem of spatial autocorrelation”, en A. J. Scott (ed.) London Papers in Regional Science, Studies in Regional Science. London: Pion, 25-55.

CNN (2004) “America Votes 2004” [URL: <http://www.cnn.com/ELECTION/2004/>. Visitado el 20 de junio de 2010].

CNN (2008) “Election Center 2008” [URL: <http://www.cnn.com/ELECTION/2008/>. Visitado el 20 de junio de 2010].

Cox, K. R. (1969) "The Voting Decision in a Spatial Context”. Progress in Geography, vol. 1, 81-117.

Cox, K. R. (1973) Conflict, Power, and Politics in the City: Geographic View. New York: McGraw Hill.

Classen, R. L. (2004) "Political Opinion and Distinctiveness: The Case of Hispanic Ethnicity". Political Research Quarterly, vol. 57, núm. 4, 609-620.

De la Garza, R. O.; DeSipio, L.; Chris Garcia, F.; Garcia, J. \& Falcón, A. (1992) Latino Voices: Mexican, Puerto Rican, and Cuban Perspectives on American Politics. Boulder: Westview Press.

DeSipio, L. (1996) Counting on the Latino Vote. Charlottesville: University of Virginia Press.

Elazar, D. J. (1984) American Federalism: A View from the States. New York: Harper and Row.

Ehsan, R. (2017) "What the Democrats Can (and must) Learn from their Unexpected Defeat". LSE US Centre. [URL: <http://blogs.lse.ac.uk/usappblog/2017/01/23/what-thedemocrats-can-and-must-learn-from-their-unexpected-defeat/>. Visitado el 4 de febrero de 2017].

Falcón, A.; De la Garza, R. O.; Garcia F.C. \& Garcia, J. A. (1991) Modes of Political Participation of Mexican-Americans, Puerto Ricans, and Cuban-Americans: Findings from the Latino National Political Survey. New York: Institute for Puerto Rican Policy.

Garcia, J. A. \& C. H. Arce (1988) "Political orientations and behaviors of Chicanos: Trying tomake sense out of attitudes and participation", en F. C. Garcia (ed.) Latinos and the Political System. Notre Dame, IN: Notre Dame University Press, 125-151. 
Getis, A. (2007) "Reflections on spatial autocorrelation". Regional Science and Urban Economics, vol. 37, núm. 4, 491-496.

GMU (2010) Voter Turnout [URL: <http://www.electproject.org/>. Visitado el 23 de junio de 2010].

Hartshorne, Richard (1950) “The Functional Approach in Political Geography”. Annals of the Association of American Geographers, vol. 44, núm. 2, 95-114.

Heppen, J. (2003) "Racial and Social Diversity and U.S. Presidential Election Regions". The Professional Geographer, vol. 55, núm. 1, 191-205.

Jaschik, S. (2010) “The Missing Latinos". Inside Higher Ed [URL: <http://www.insidehighered.com/news/2010/05/14/latinos>. Visitado el 16 de mayo de 2010].

Johnston, R. J. (1974) "Local Effects in Voting at a Local Election". Annals of the Association of American Geographers, vol. 64, núm. 3, 418-429.

Johnston, R. J. (1977) "The Geography of Federal Allocations in the United States". Geoforum, vol. 8, núm. 5-6, 319-326.

Johnston, R. J. (1979) Political, Electoral, and Spatial Systems. Oxford: Clarendon Press.

Johnston, R.; Jones, K.; Propper, C. \& Burgess, S. (2007) "Region, Local Context, and Voting at the 1997 General Election in England". American Journal of Political Science, vol. 51, núm. 3, 640-654.

Jones, K.; Johnston, R. J. \& Pattie, C. J. (1992) "People, Places and Regions: Exploring the Use of Multi-Level Modeling in the Analysis of Electoral Data". British Journal of Political Science, vol. 22, núm. 3, 343-380.

Kim, J. \& Mueller, C. W. (1978) Introduction to factor analysis: what it is and how to do it. Beverly Hills: Sage Publications.

Lee, M. Y. H. (2015) “Analysis: Donald Trump's false comments connecting Mexican immigrants and crime". The Washington Post. [URL: <https://www.washingtonpost.com/news/fact-checker/wp/2015/07/08/donald-trumps-false-comments-connecting-mexican-immigrants-and-crime/?utm_term $=.872648389$ ce5 $>$. Visitado el 23 de marzo de 2017).

Lopez, M. H. (2009) "The Hispanic Vote in the 2008 Election". Pew Hispanic Trust [URL: $<$ http://pewhispanic.org/files/reports/98.pdf $>$. Visitado el 12 de marzo de 2010].

McClain, P. D. \& Garcia, J. A. (1993) "Expanding Disciplinary Boundaries: Black, Latino, and Racial Minority Group Politics in Political Science", en A. W. Finifter (ed.) Political Science: The State of the Discipline, II. Washington, D.C.: American Political Science Association, 247-279.

McPhail, I. R. (1971) “The Vote for Major of Los Angeles in 1969”. Annals of the Association of American Geographers, vol. 61, núm. 4, 744-758.

Mercer, J. \& Agnew J. A. (1988) "Small Worlds and Local Heroes: The 1987 General Election in Scotland". Scottish Geographical Magazine, vol. 104, núm. 3, 136-145.

Moran, P. A. P. (1950) "Notes on Continuous Stochastic Phenomena". Biometrika, vol. 37, núm. 1-2, 17-33.

Pattie, C. J. \& Johnston, R. J. (1990) “Embellishment and Detail? The Changing Relationship between Voting, Class, Attitudes and the Core. Periphery Division of Great Britain 19791987'. Transactions of the Institute of British Geographers, vol. 15, núm. 2, 205-226.

Pattie, C. J. \& Johnston, R. J. (2000) "People Who Talk Together Vote Together": An Exploration of Contextual Effects in Great Britain". Annals of the Association of American Geographers, vol. 90, núm. 1, 41-66.

Pew Research Center (2016) "2106 Campaign: Strong Interest, Widespread Dissatisfaction”. Pew Research [URL: <http://assets.pewresearch.org/wp- 
content/uploads/sites/5/2016/07/07-07-16-Voter-attitudes-release.pdf $>$. Visitado el 15 de abril de 2017).

Prescott, J. R. V. (1959) "The Function and Methods of Electoral Geography”. Annals of the Association of American Geographers, vol. 49, núm. 3, 296-304.

Rodriguez, D. (2002) Latino National Political Coalitions: Struggles and Challenges. New York: Routledge.

Shaw, D.; de la Garza, R. O. \& Lee, J. (2000) "Examining Latino Turnout in 1996: A Three State, Validated Survey Approach”. American Journal of Political Science, vol. 44, núm. 2, 338-346.

Shelley, Fred M. \& Archer, J. Clark (1984) "Political Habit, Political Culture, and the Electoral Mosaic of a Border Region”. Geographical Perspectives, vol. 54, núm. 1, 7-20.

Shelley, Fred M. \& Archer, J. Clark (1989) "Sectionalism and Presidential Politics: Voting Patterns in Illinois, Indiana, and Ohio". Journal of Interdisciplinary History, vol. 20, núm. 2, 227-255.

Shelley, Fred M.; Archer, J. Clark; Davidson, Fiona M. \& Brunn, Stanley D. (1996) Political Geography of the United States. New York: Guilford Press.

Shelley, Fred M.; Johnston, Ron. J. \& Taylor, Peter J. (1990) "Developments in electoral geography", en R. J. Johnston, F. M. Shelley \& P. J. Taylor (eds.) Developments in Electoral Geography. London: Routledge, 1-11.

Tabachnick, B. G. \& Fidell, L. S. (2007) Using Multivariate Statistics. Boston: Pearson (5a ed).

Taylor, P. J. \& Johnston, R. J. (1979) Geography of Elections. London: Croom Helm.

Tobler, W. R. (1970) "A computer movie simulating urban growth in the Detroit region". Economic Geography, vol. 46 núm. 2, 234-240.

Torres, M. de los A. (1988) "Cuban American Politics", en C. Garcia (ed.) Latinos and the Political System. Notre Dame, Indiana: Notre Dame Press, 81-98.

Trubowitz, P. (1998) Defining the National Interest: Conflict and Change in American Foreign Policy. Chicago: University of Chicago Press.

Tunstall, H.; Rossiter, D. J.; Pattie, C. J.; MacAllister, I.; Johnston, R. J. \& Dorling, D. F. L. (2000) "Geographical Scale, the «Feel-Good Factor» and Voting at the 1997 General Election in England and Wales". Transactions of the Institute of British Geographers, vol. 25, núm. 1, 51-64.

U. S. Census Bureau (2016) American Community Survey. [URL: <http://factfinder.census.gov/>. Visitado el 3 de febrero de 2017].

Uhlaner, C. J.; Cain, B.E. \& Kiewiet, D. R. (1989) "Political Participation of Ethnic Minorities in the 1980s". Political Behavior, vol. 11, núm. 3, 195-231.

Ward, N. (2002) "Representing rurality? New labour and the electoral geography of rural Britain". Area, vol. 34, núm. 2, 171-181.

Warf, Barney \& Leib, Jonathan (eds.) (2011) Revitalizing Electoral Geography. Farnham (RU): Ashgate.

Watrel, Robert (2001) Sectionalism, Coalitions, and Local-National Politics: A Geographical History of Presidential and Gubernatorial Elections in North Dakota, 1889-2000. Tesis doctoral, Department of Geography, University of Nebraska.

Weichelt, R. (2008) Scale Factors in Hispanic Voting. Tesis doctoral, Department of Anthropology and Geography, University of Nebraska.

Weichelt, R. (2010) "Does a Hispanic Region of South Texas Exist? An Electoral Analysis of U.S. Presidential Elections, 1952 to 2008 in the State of Texas". Southwestern Geographer. vol. 14, 88-121. 
Weichelt, R. \& Zeitler, E. (2012) "Multi-Scalar Cartographic Analysis of 2008 and 2010 Election Returns in Wisconsin, USA". Journal of Maps, vol. 8, núm. 3, 312-319.

Welch, S. \& Hibbing, J. R. (1984) "Hispanic Representation in the U.S. Congress". Social Science Quarterly, vol. 65, núm. 2, 328-335.

Wright, J.K. (1944) "Training for Research in Political Geography". Annals of the Association of American Geographers, vol. 34, núm. 4, 190-201. 